\title{
Economic Improvement of Power Factor Correction: A Case Study
}

\author{
Kassem Wahab, Mohamad Rahal*, Roger Achkar \\ Department of Computer and Communications Engineering, Faculty of Engineering, American University of Science and \\ Technology, Beirut, Lebanon \\ Email: ^mrahal@aust.edu.lb
}

How to cite this paper: Wahab, K., Rahal, M. and Achkar, R. (2021) Economic Improvement of Power Factor Correction: A Case Study. Journal of Power and Energy Engineering, 9, 1-11.

https://doi.org/10.4236/jpee.2021.96001

Received: April 23, 2021

Accepted: June 5, 2021

Published: June 8, 2021

Copyright ( 2021 by author(s) and Scientific Research Publishing Inc. This work is licensed under the Creative Commons Attribution International License (CC BY 4.0).

http://creativecommons.org/licenses/by/4.0/

\begin{abstract}
Power factor (PF) is simply an expression of energy efficiency, which is always expressed in terms of percentage. Technically, PF is a ratio of real power in Kilowatts to the apparent power, which is always expressed in kilovolts amperes. In AC power analysis, power is always expressed in three ways, the real power $(P)$, reactive power $(Q)$, and the apparent power $(S)$. The real power is the work useful power, while the reactive power is the wasted power in the 3-phase AC system, and the apparent power is the vectorial sum of the two powers. The increase of reactive power will reduce the presence of real power, thus making the power to be more expensive. In this paper, we will analyze the importance of improving the power factor by applying a bank of capacitors to a case study in Lebanon. Analysis of the economic improvement in the application of power factor correction is carried out. The result shows a reduction of 12 percent in the total cost.
\end{abstract}

\section{Keywords}

Power Factor, Reactive Power, kVAR, Inductive, Apparent Power, Active Power

\section{Introduction}

In the production of power, there are a lot of inductors used in AC machines like transformers and motors. Inductances are caused by the magnetic fields, which are produced by the currents flowing in the electrical circuit. Basically, the coils of wires are employed as the coil increases the magnetic field coupling. In the process of transmission of power, the power factor shows the effectiveness of the electricity used. The improvement of the power factor is very significant economically as it helps to reduce the electricity bill. Improving the power factor is a 
verified technique of improving the effective usage of the electricity through the utilities as well as the end-users (final consumers of electricity). The economic benefit for the final consumer of electricity is lower power losses in the cables as well as in the transformer. Increased power factor also helps in reducing the electricity bills and improving voltage conditions as the benefits of utilities from the system release capacity [1].

The real power is taken as the power for producing work, which is always given in watts (kilowatts); the reactive power, which is due to the inductors and capacitors, is not used to do any work (it is a wasted power), but it is needed in AC 3-phase power system for the equipment to operate. Several industrial loads are inductive, like the transformers, motors, industrial furnaces, and induction furnaces [2]. The current drawn by the inductive load includes two key components: the power-producing current and the magnetizing current. The magnetizing current is needed to sustain the electromagnetic field in the component and generate reactive power [3]. The inductive load will draw current, which always lags the voltage.

When the harmonics are absent, the apparent power (demanded power) is composed of the vectorial sum of both, the real power and the reactive power, thus showing how much power the electrical power will use. The PF also is the cosine angle between the current and the voltage in the phasor diagram. For the electrical loads which are inductive like motor, they consume of about 80 percent to 90 percent (power factor) which is delivered to them while the remaining percentage of power (10 percent to 20 percent) delivered is wasted as they are employed to establish the electromagnetic field in the machines. The electromagnetic field will expand and collapse, so the drawn power to the field in one instant is just a return to the supply of electrical power in the subsequent instant [4]. Thus, the mean power drawn by the magnetic field will remain zero, and the reactive power doesn't appear in the meter of kilowatts-hour. The magnetic current will generate reactive power. Even though it does not do useful work, it will circulate between the places and the generator to heavily drain the power source [5].

To reduce the reactive power, some banks of capacitors are added which is an economical technique to adjust the power factor. As the current via an inductive load will lag the voltage, the current will lead the voltage in a capacitor. Therefore, the capacitors are added to serve as leading reactive current producers to help counter the lagging reactive current in electrical transmission [6]. The release of capacity implies that the total current flowing will be minimized as the system's power factor. This will allow the extra load to be included and served by the available system. In case the equipment like the generators, cables, and transformers might be thermally overloaded, by increasing the power factor, the current will be minimized and overload condition will be eliminated.

Basically, the correction of power factor should be encouraged by applying penalties which is introduced by some utilities. When entirely considered, there may also be some economic factors that may result in capacitors' addition for power factor correction, which gives a justifiable investment return [7]. There 
are also other savings like the reduction in the distribution losses, increased voltage reduction, and current increased facilities. Even though the real power often produces little in the savings of cost and is smaller than the saving to be gained from the power factor penalties reduction.

This paper is organized as follow. Section 2 presents the power factor correction background along with materials and methods. The full details about mathematical calculations are explained. Section 3 presents a case study of one juice factory for the period of four years. Appropriate conclusion is drawn in Section 4.

\section{Background, Materials, and Methods}

\subsection{Background}

The product of current $I$ and the voltage $V$ at any given point is known as instantaneous power, and it is given by the equation below

$$
P=V I(\text { Watt })
$$

Let's consider the average power $P$ in the circuit, which has resistance and inductance, the following equation gives the power factor

$$
\text { Power factor }=\frac{\text { Real Power }}{\text { Apparent power }}=\cos \phi
$$

The phasor diagram of the three powers is illustrated in the following diagram For real power from Figure 1

$$
\begin{gathered}
p=V_{m} \sin w t I_{m} \sin (w t-\Phi) \\
p=V_{m} I_{m} \sin w t \sin (w t-\Phi) \\
p=V_{m} I_{m}\left\{\frac{1}{2}[\cos (w t-w t+\Phi)-\cos (w t+w t-\Phi)]\right\} \\
p=\frac{1}{2} V_{m} I_{m}(\cos \phi-\cos (2 w t-\Phi))
\end{gathered}
$$

Thus the average power $p=\frac{1}{2} V_{m} I_{m} \cos \Phi$

$$
\begin{aligned}
& p=\frac{1}{2} \sqrt{2} V \sqrt{2} I \cos \Phi \\
& p=V I \cos \Phi(\text { Watt })
\end{aligned}
$$

And the reactive power is given by the following equation.

$$
Q=V I \sin \Phi(\text { Watt })
$$

As stated, that the most suitable and common way of improving the power factor is to use capacitor banks; the following diagram illustrates the circuit diagram of this illustration.

The phasor diagram of the power with the reactive power after and before power factor correction is illustrated in the following diagram. 


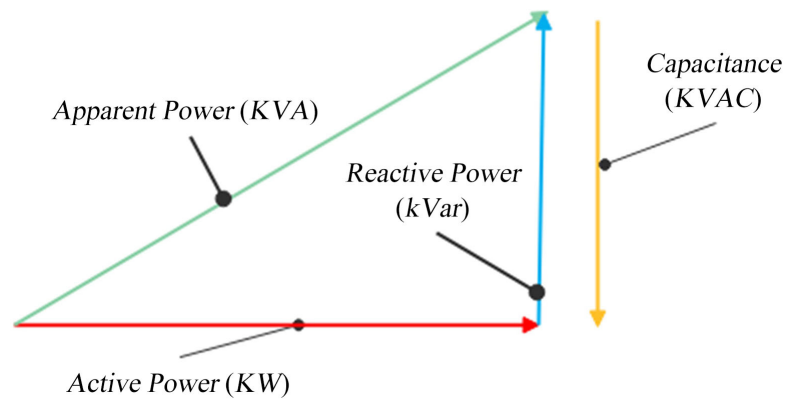

Figure 1. Phasor diagram of the power factor.

Figure 2 shows that the effective reactance power is obtained by getting the difference between inductive power and capacitive power. The apparent power of the system, therefore, can be calculated using the following equation.

$$
S=\sqrt{\text { real power }^{2}+(\text { Inductive power }- \text { Capacitive power })^{2}}
$$

Figure 3 shows that with the addition of capacitance, the value of refractive power moved from $Q_{L 1}$ to $Q_{L 2}$. This movement occurs with a constant real power value, making the angle's value to reduce in value from $\Phi_{1}$ to $\Phi_{2}$. When the value of the angle is reduced, it means that the power factor is increased [8]. It can also be seen in Figure 3 that inductive power increases the reactive power while the capacitive power reduce the reactive power. Also from Figure 3, it can be seen the effective reactive power is the difference between the inductive power and capacitive power [9]. Therefore, the addition of a capacitor will help in the reception of the reactance, which therefore reduces the reactive power. The apparent power in the AC power can be given in the following equations.

$$
\begin{gathered}
S=\sqrt{\text { Reactive power }^{2}+\text { Active power }^{2}} \\
S=\sqrt{(I V \sin \Phi)^{2}+(I V \cos \Phi)^{2}} \\
S=V I(\cos \Phi+j \sin \Phi)
\end{gathered}
$$

\subsection{Materials and Methods}

For an AC power system, which is connected in three phases, the capacitor can either be connected in a star configuration or delta configuration. An improved power factor minimizes the load in the conductor and transformers installations. In an ideal situation, the power factor would be 1, which means that a system with a good or recommended power factor will always approach 1. Improving the power factor results in increasing the infrastructure's capacity and reduces the losses of the cable's transformers and losses. Improving the power factor helps in lowering the losses in the alternator coppers [10]. Improved power factor helps reduce the demand charges of the kVA for a larger electricity consumer if a power factor penalty is introduced. Power factor correction reduces the load current. The addition of static capacitor in a delta connection is illustrated in Figure 4, while the addition of static capacitor in a star connection is illustrated 
in Figure 5.

We can make a good analysis of the reactive power using Figure 6 as an example

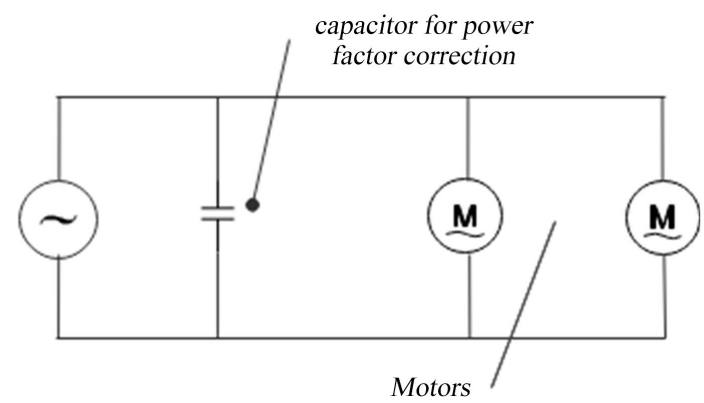

Figure 2. Circuit diagram of a capacitor for power factor rectification.

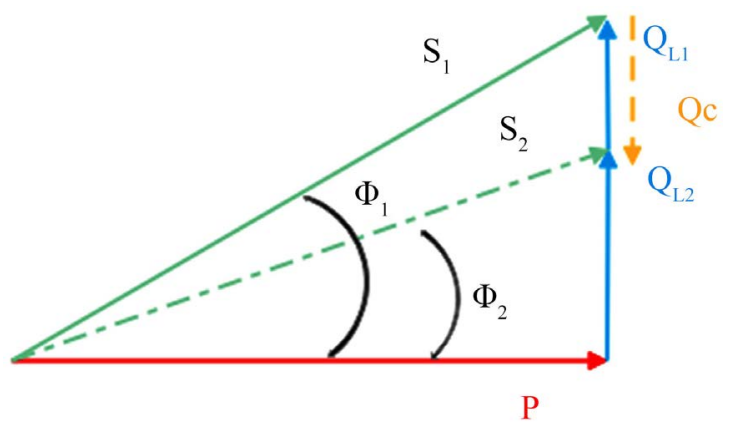

Figure 3. Phasor diagram of the power with the reactive power after and before power factor correction.

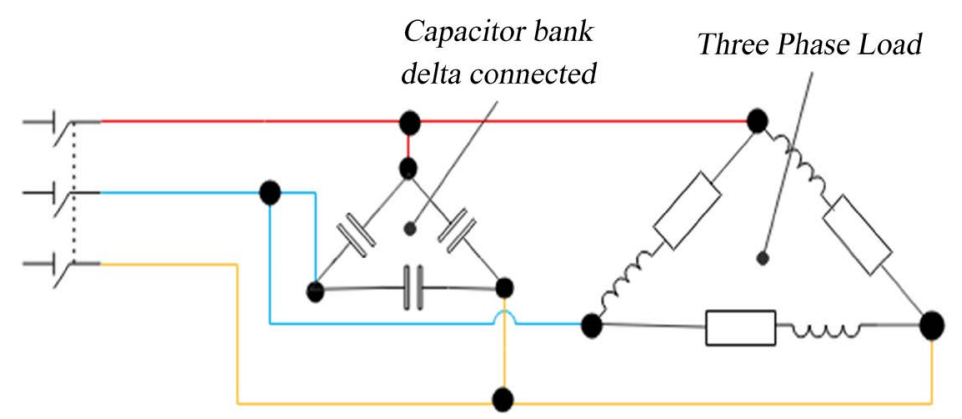

Figure 4. Addition of static capacitor in delta configuration.

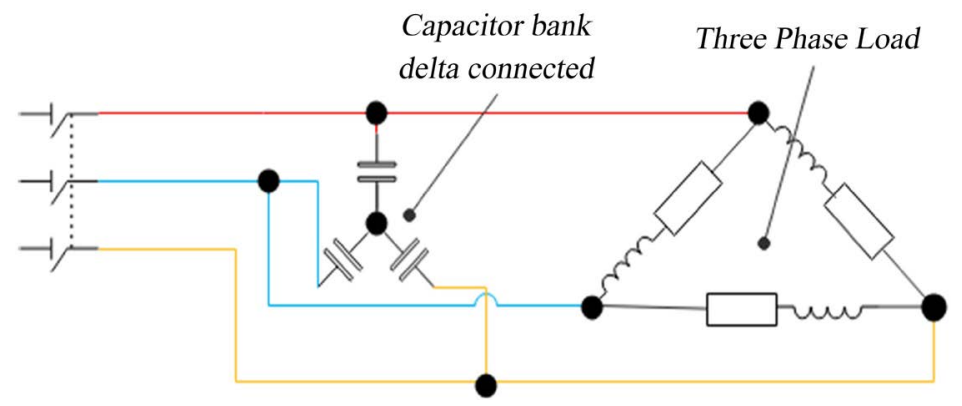

Figure 5. Addition of static capacitor in delta configuration. 


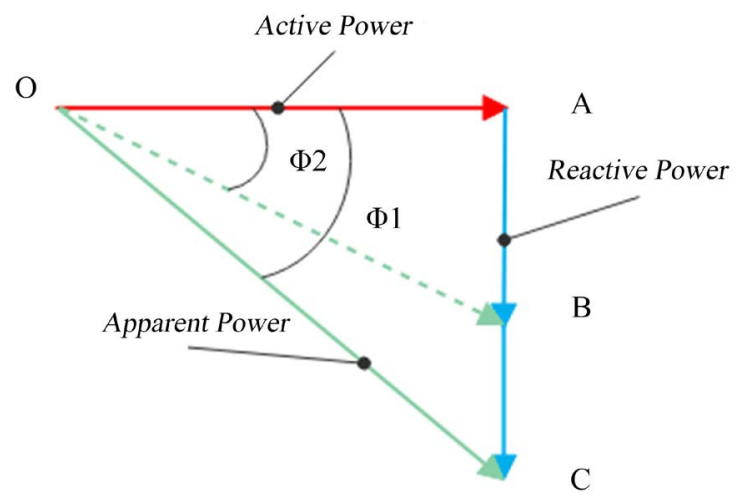

Figure 6. Power factor correction.

The supplied leading kVAR by the correction of the power factor equipment is given by the following equations.

$$
\begin{gathered}
B C=A C-A B \\
B C=\mathrm{kVAR}_{1}-\mathrm{kVAR}_{2} \\
B C=O A \tan \Phi_{1}-O A \tan \Phi_{2} \\
B C=O A\left(\tan \Phi_{1}-\tan \Phi_{2}\right) \\
B C=P\left(\tan \Phi_{1}-\tan \Phi_{2}\right)
\end{gathered}
$$

The value of capacitance required for the correction of power is given below;

$$
\begin{gathered}
B C=I_{c} V \\
I_{c}=\frac{B C}{V}
\end{gathered}
$$

The capacitive reactance $X_{c}$ is thus given as below

$$
X_{c}=\frac{V}{I_{c}}=\frac{1}{2 \pi f C}
$$

From equation 6 we can obtain equation 7 as the value of capacitance as below

$$
C=\frac{I_{c}}{2 \pi f V}
$$

\subsubsection{Depreciation of Banks of Capacitors}

The depreciation is the loss in value that results from equipment and machinery usage during a given period of time. During that particular time of usage, the cost of using capital is the loss or depreciation of that value but not its purchase price. The rate of depreciation is the rate of such a loss in value, and the following equation gives the charges in the annual depreciation;

$$
\text { Annual Depreciation Charges }=\frac{\text { Original Costs }- \text { Salvage value }}{\text { The life span of the plan }(\text { years })}
$$

\subsubsection{Calculation of Capacitance}

Taking an example of obtaining the required capacitance required to raise the power factor from $60 \%$ to $90 \%$ lagging power factor. The voltage is taken as 400 
$\mathrm{V}$ and at a frequency of $50 \mathrm{~Hz}$.

The input power $=5 \mathrm{~kW}$

The actual power factor $=\cos \Phi_{1}=0.6$

The desired power factor $=\cos \Phi_{2}=0.9$

$$
\begin{aligned}
& \Phi_{1}=\cos ^{-1}(0.60)=53.13^{\circ} \\
& \Phi_{2}=\cos ^{-1}(0.90)=25.84^{\circ}
\end{aligned}
$$

The desired capacitive power (kVAR) to increase Power Factor from 0.60 to 0.90 .

The desired capacitive power $(\mathrm{kVAR})=P\left(\tan \Phi_{1}-\tan \Phi_{2}\right)$

$$
\mathrm{kVAR}=5 \mathrm{~kW} \times(1.333-0.4843)
$$

The desired capacitive power $=10.188 \mathrm{kVAR}$

The $\mathrm{kVAR}=10.188$

From Equation (6), $X_{c}=\frac{V}{I_{c}}=\frac{1}{2 \pi f C}$

$$
\begin{gathered}
I_{c}=2 \pi f C V \\
I_{c}=125663.7 \times C
\end{gathered}
$$

And

$$
\begin{aligned}
\mathrm{kVAR}= & \frac{V I_{c}}{1000}=400 \times 125663.7 \times C \\
& I_{c}=50265.48 \times C
\end{aligned}
$$

As a result, we got the value of the capacitance: Figure 7

$$
C=202.7 \mu \mathrm{F}
$$

\section{Results}

Power factor correction gives numerous advantages:

- Reduces consumption bills

- Improved voltage

- Increases the capacity of grid

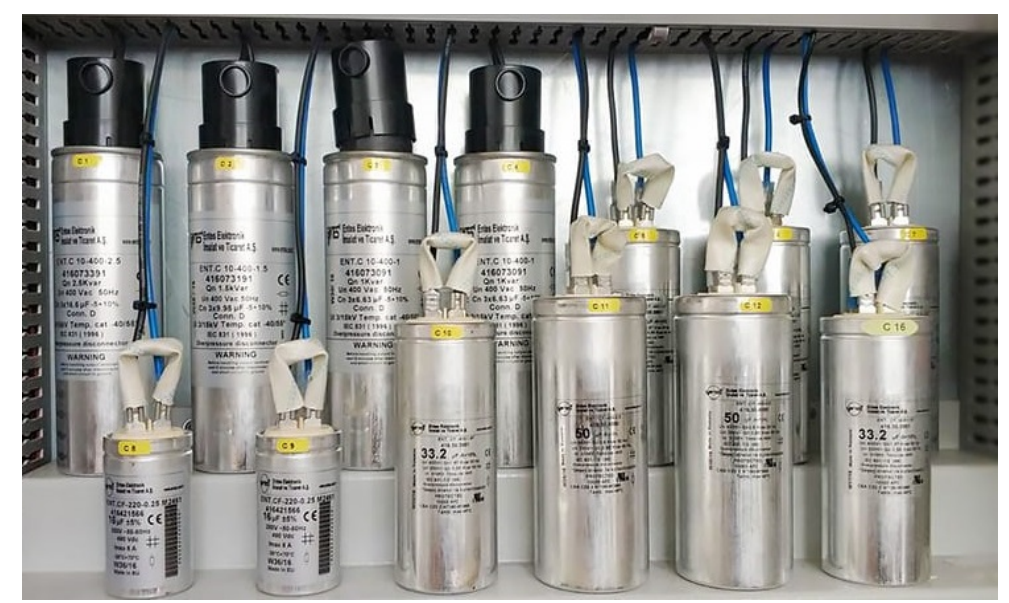

Figure 7. A bank of capacitors for power factor correction [11]. 


\section{Case Study}

BALQIS is a factory in south Lebanon engaged in fruit juice production business. This study is based on their data provided for 9 machines for the past four years. The aim from this study is to correct the power factor from 0.8 to 0.9 .

Table 1 illustrates the annual demand of the power before the application of the capacitors bank. Also, this table shows different parameters related to power factor, the annual consumption and the cost of $\mathrm{kWh}$. At the end of the table, the total annual cost and the total of the four years cost are illustrated.

Table 2 illustrates the annual demand of the power after the application of the capacitors bank. Also, this table shows different parameters related to power factor, the annual consumption and the cost of $\mathrm{kWh}$. It is clearly shows the drop of the actual demand power $(\mathrm{kW})$ that cause the reducing of the total annual power cost. At the end of the table, the total annual cost and the total of the four years cost are illustrated.

Figure 8 compares the total cost before and after the correction of the power factor in blue and orange respectively.

Table 3 illustrates the annual demand of the power before and after the application of the capacitors bank. Also, this table shows different parameters related to power factor such as the size of the capacitor needed, the annual maintenance cost of the capacitors bank, the upgrades occurred after the increasing of the power demand and the depreciation cost. At the end of the table, the total saving cost after the application of the capacitors bank and the correction of the power factor is calculated.

Figure 9 is showing the cost of power factor raise above 0.9 and below 1 for the same case study above.

Table 1. Total annual cost of power consumption without the application of power factor correction.

\begin{tabular}{ccccc}
\hline Year & 2017 & $\mathbf{2 0 1 8}$ & $\mathbf{2 0 1 9}$ & $\mathbf{2 0 2 0}$ \\
\hline $\begin{array}{c}\text { Actual Demand } \\
\text { Power (kVA) }\end{array}$ & 320 & 320 & 340 & 360 \\
Power factor & 0.8 & 0.8 & 0.8 & 0.8 \\
$\begin{array}{c}\text { Uncorrected } \\
\text { demand Power (kW) } \\
\text { Demand Charge/ } \\
\text { KW (LBP) }\end{array}$ & 400 & 400 & 425 & 450 \\
$\begin{array}{c}\text { Total consumed/ } \\
\text { Month (kWh) }\end{array}$ & 144 & 144 & 144 & 144 \\
$\begin{array}{c}\text { Total consumed/ } \\
\text { Year (kWh) }\end{array}$ & $1,152,000$ & $1,152,000$ & $1,224,000$ & $1,296,000$ \\
Total Annual \\
Cost (LPB) \\
$\begin{array}{c}\text { Total cost/ } \\
\text { Four years (LBP) }\end{array}$
\end{tabular}


Table 2. Total annual cost of power consumption with the application of power factor correction.

\begin{tabular}{ccccc}
\hline Year & $\mathbf{2 0 1 7}$ & $\mathbf{2 0 1 8}$ & $\mathbf{2 0 1 9}$ & $\mathbf{2 0 2 0}$ \\
\hline $\begin{array}{c}\text { Actual Demand } \\
\text { Power (kW) }\end{array}$ & 320 & 320 & 340 & 360 \\
Power factor & & & & \\
Corrected demand \\
Power (kW) \\
kW Demand \\
Charge (LBP) \\
$\begin{array}{c}\text { Total consumed/ } \\
\text { Month (Kwh) } \\
\text { Total consumed/ } \\
\text { Year (kWh) }\end{array}$
\end{tabular}

Table 3. Total annual cost of power consumption with the application of power factor correction.

\begin{tabular}{ccccc}
\hline Year & $\mathbf{2 0 1 7}$ & $\mathbf{2 0 1 8}$ & $\mathbf{2 0 1 9}$ & $\mathbf{2 0 2 0}$ \\
\hline Uncorrected Total cost/Year & $165,888,000$ & $165,888,000$ & $176,256,000$ & $186,624,000$ \\
Corrected Total cost/Year & $147,456,000$ & $147,456,000$ & $156,672,000$ & $165,888,000$ \\
Leading kVAR & 70 & 70 & 80 & 85 \\
Capacitor cost (LBP) & $3,375,000$ & - & - & - \\
Maintenance cost/year & - & 337,500 & 385,700 & 409,800 \\
Upgrade cost & - & - & 482,000 & 241,000 \\
Depreciation/12 years lifecycle & 281,138 & 281,138 & 293,633 & 343,613 \\
Total cost saving/Year & $14,775,863$ & $17,813,363$ & $18,422,668$ & $19,741,588$ \\
Total Saving/Four Years (LBP) & \multicolumn{5}{c}{$70,753,480$} \\
\hline
\end{tabular}

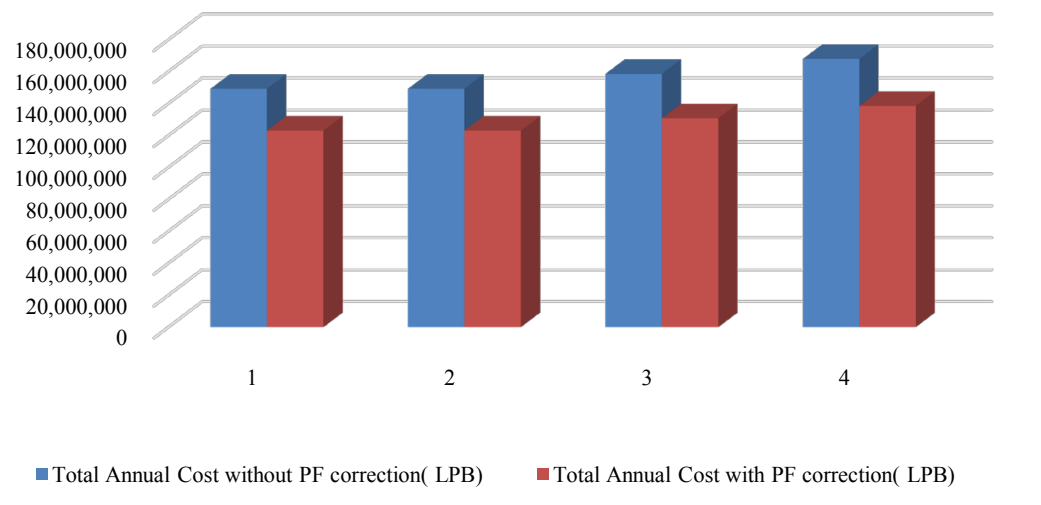

Figure 8. Cost before and after application of powerfactor improvement. 


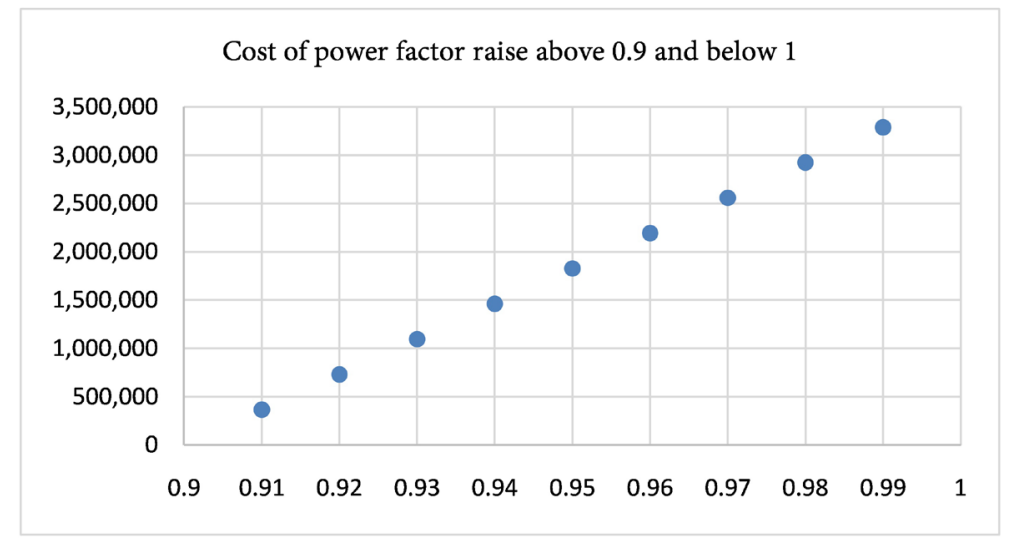

Figure 9. Cost of power factor raise above 0.9 and below 1 .

\section{Discussion and Conclusion}

The above shows that the cost of electrical energy is relatively higher for the uncorrected power factor. The reduction of the electricity bill's cost implies that the amount of electrical energy wasted is reduced, which makes the cost of electrical energy to reduce. The reduction of the voltage drop also implies a reduction in power loss, which also replicates the electricity bill savings. Therefore, the usage of capacitors to increase the power factor is very significant in ensuring that the cost of electricity is reduced, making it a very economical technique in electrical transmission and usage.

Lebanon currently has a maximum electricity-production capacity of 2000 megawatts (MW), less than the summer peak demand of $3400 \mathrm{MW}$. So, correcting the PF close to unity would save a lot of power and close the gap between the production and demand.

To encourage the people of Lebanon to correct the power factor, it is suggested by the World Bank in their report in May 2020 to Electricity of Lebanon. Penalty should apply on any power factor drops below 0.8 .

In summary, power factor improvement is very significant in the AC electrical system as it causes an increase in the demanded kVA charges of the final consumers' electricity bills by the utilities. Therefore, in ensuring the most suitable conditions for a power system in both economic (business) and engineering point of view, it is very significant for any power system having various equipments like the alternator, switchgear, transmission, and the transformer close to the unity power factor. Having a power factor that is approaching unity, the total reduction in the electricity cost can be realized effectively and economically. The above analysis has been archived to have a good performance of the electric power system. It is important and economical to operate the electrical system at a higher power factor between 0.9 and 1. For the installation of extra auxiliaries like the switchgear, alternators, transformers, and bus bars, the reactive power may increase; therefore, through calculation, a suitable amount of capacitance will be required to help counter the addition of the inductive power in the system, which may lower the power factor. 


\section{Conflicts of Interest}

The authors declare no conflicts of interest regarding the publication of this paper.

\section{References}

[1] Adefarati, T. (2013) Economic and Industrial Application of Power Factor Improvement. CRC Press, Hull.

[2] Joshi, H. (2018) Residential, Commercial and Industrial Electrical Systems: Equipment and Selection. Tata McGraw-Hill Education, Hull.

[3] Whitfield, J. (2014) Electrical Craft Principles. IET, Liverpool.

[4] (2018) Resources, Market-Oriented Program Planning Study: Hearings before the Committee on Energy and Natural Resources, United States Senate, Ninety-fifth Congress, First Session on the Energy Research and Development Administration's Market-oriented Program Planning Study. U.S. Government Printing Office, Chicago.

[5] Clayton, A.E. (2019) Power Factor Correction: Explaining the Meaning and Importance of Power Factor, and Describing Methods for the Improvement of Power Factor. Sir I. Pitman \& Sons, Limited, Liverpool.

[6] Paschal, J. (2019) Practical Guide to Power Factor Correction and Harmonics and Your Electric Bill. EC\&M Books/Intertec Pub, Liverpool.

[7] Teo, H.S. (2013) Designing Power Factor Correction Circuit for Fluorescent Lamp Ballast. Jabatan Kejuruteraan Elektrik, Fakulti Kejuruteraan, Universiti Malaya, New York.

[8] Natarajan, R. (2018) Power System Capacitors. CRC Press, Washington DC. https://doi.org/10.1201/9781420027204

[9] Rashid, M.H. (2014) Power Electronics Handbook: Devices, Circuits, and Applications. Elsevier, Amsterdam.

[10] Willis, L. (2019) Power Distribution Planning Reference Book. CRC Press, Florida.

[11] EEP-Electrical Engineering Portal. (2019) Reactive Power and Power Factor Correction Essentials to ALWAYS Keep on Mind. Electrical-Engineering-portal.com. 